\title{
SISTEM PENGAMBILAN KEPUTUSAN DALAM PEMILIHAN SEPEDA MOTOR MATIC HONDA DENGAN MENGGUNAKAN METODE ANALYTICAL HIERARCHY PROCESS (STUDI KASUS: CV. DARMIN MOTOR KOTA TANGERANG)
}

\author{
Eka W Fridayanthie1, Ahmad Ahzar Alfiansyah² \\ Program Studi Sistem Informasi \\ Universitas Bina Sarana Informatika \\ Jl. Kamal Raya No. 18 Ringroad Barat, Cengkareng, Jakarta Barat \\ Email : eka.ewf@bsi.ac.id ahmadahzar22@gmail.com
}

\begin{abstract}
In the selection of Honda Honda motorcycles, of course consumers want to get the best and right choice. On CV. Darmin Motor Tangerang City has a factor in the assessment. This assessment is based on criteria and alternatives such as price, design, product quality and other brands of Honda Motorcycle. Almost every consumer wants a matic motorcycle that is affordable, fuel efficient and comfortable to use. This decision support system uses the method (AHP) as a process in determining the best matic motorbikes. This can be useful to facilitate a decision-making related to a problem of selecting Honda Motorcycle so that there will be many criteria and alternatives for consumers. In this study, data acquisition was obtained from the results of the questionnaire. The data that has been obtained is processed using Microsoft Excel so ftware and expert choice software. The results of the study using the Expert Choice Software application showed that the first rank was Beat Sport CBS with a value of 0.514 or $51.4 \%$ next Vario 125 CBS with a value of 0.300 or $30.0 \%$ and ranked last 0.187 or $18.7 \%$.
\end{abstract}

Keywords: Selection of Honda Matic Motorcycles, Decision Support Systems, Analytical Hierarchy Process, Expert Choice 2000

\section{PENDAHULUAN}

Perkembangan transportasi sepeda motor saat ini sudah menjadi barang yang sangat penting bagi semua orang, berarti sepeda motor merupakan sebuah kebutuhan yang tergolong primer. Hal ini menunjukkan bahwa fungsi sepeda motor sangat bermanfaat untuk semua orang, disamping untuk alat transportasi sepeda motor juga digunakan untuk menambah penghasilan bagi sebagian profesi tertentu. Persaingan pada perusahaan otomotif di Indonesia semakin ketat, dimana hal tersebut dipengaruhi oleh meningkatnya kebutuhan masyarakat terhadap sepeda motor.
Di Indonesia terdapat beberapa jenis kategori sepeda motor matic yaitu diantarannya, motor beat, motor vario, motor scoopy. Mayoritas masyarakat Indonesia memilih untuk menggunakan motor matic karena pemakaiannya yang lebih mudah, nyaman, dan praktis. Motor matic ini lebih digemari dibandingkan dengan motor bebek untuk saat ini terutama untuk dipakai seharihari, maka tidak akan heran produsen kendaraan roda dua berlomba-lomba menghadirkan motor matic mereka dengan kelebihan masing-masing yang mereka miliki. 
Dalam pemilhan sepeda motor matic, tentu para konsumen ingin mendapatkan pilihan yang terbaik dan tepat. Hampir setiap konsumen menginginkan sepeda motor matic yang harganya terjangkau, irit bahan bakar dan nyaman digunakan. Sistem pendukung keputusan ini menggunakan metode (AHP) sebagai proses dalam menentukan sepeda motor matic terbaik (Bayu Rianto, 2016).

Berdasarkan latar belakang tersebut, maka peneliti tertarik untuk melakukan penelitian pada perusahaan sepeda motor matic honda dengan judul : Analisa Pemilihan Sepeda Motor Matic Honda Dengan Menggunakan Metode Analytical Hierarchy Process Pada CV Darmin Motor Kota Tangerang.

\section{LANDASAN TEORI}

\subsection{Pengambilan Keputusan}

Menurut Basuki \& Cahyani (2016:1) mengemukakan bahwa"Pengambilan keputusan merupakan suatu hal yang sangat kompleks dengan melibatkan manusia (people) dan informasi (information)".

"Pengambilan keputusan merupakan hasil suatu proses pemilihan dari berbagai alternatif tindakan yang mungkin dipilih dengan mekanisme tertentu, dengan tujuan untuk menghasilkan keputusan yang terbaik". (Sasongko et al., 2017)

\subsection{Sistem Pendukung Keputusan}

Menurut Pratiwi (2016:2) "Pengambilan keputusan merupakan sesuatu yang akan dihadapi oleh manusia. Keputusan yang diambil biasanya karena ada pertimbangan tertentu atau atas dasar logika, ada alternatif terbaik dari beberapa alternatif yang harus dipilih, dan ada tujuan yang akan dicapai".

"Sistem pendukung keputusan adalah sekumpulan elemen yang saling berhubungan untuk membentuk suatu kesatuan dalam proses pemilihan berbagai alternatif tindakan guna menyelesaikan suatu masalah, sehingga masalah tersebut dapat diselesaikan secara efektif dan efisien". (Saefudin, 2014).

\subsection{Sistem Pendukung Keputusan}

"Sistem pendukung keputusan adalah sekumpulan elemen yang saling berhubungan untuk membentuk suatu kesatuan dalam proses pemilihan berbagai alternatif tindakan guna menyelesaikan suatu masalah, sehingga masalah tersebut dapat diselesaikan secara efektif dan efisien”. (Saefudin, 2014).

\subsection{AHP (Analytical Hierarchy Process)}

Pada umumnya, Proses pengambilan keputusan adalah memilih suatu alternatif tertentu. Menurut Pratiwi (2016:27) AHP merupakan teknik pengambilan keputusan/optimasi multivariate yang digunakan dalam analisis kebijaksanaan. Pada hakekatnya AHP merupakan suatu model pengambil keputusan yang komprehensif dengan memperhitungkan halhal yang bersifat kualitatif dan kuantitatif.

\section{Prinsip Dasar AHP}

Menurut Pratiwi (2016:28) pada dasarnya langkah-langkah dalam menyelesaikan suatu permasalahan dengan metode AHP akan meliputi:

1. Membuat Hierarki

Persoalan yang akan diselesaikan, diuraikan menjadi unsur-unsurnya, yaitu kriteria dan alternatif, kemudian disusun menjadi struktur hierarki.

2. Penilaian Kriteria dan Alternatif

Untuk berbagai persoalan yang ada, skala 1 sampai 9 adalah skala terbaik dalam mengekspresikan pendapat. Nilai dan definisi pendapat Kualitatif dari skala perbandingan ini dapat dilihat tabel II.1 berikut.

3. Penentuan Prioritas (Synthesis of Priority)

Untuk setiap kriteria dan alternatif, akan perlu dilakukan perbandingan 
berpasangan (pairwise comparisions). Nilai-nilai perbandingan relatif kemudian akan diolah untuk menentukan suatu peringkat alternatif dari seluruh alternatif.

4. Konsistensi Logis ( Logical Consistency)

Konsistensi memiliki dua makna. Pertama, objek-objek yang serupa bisa dikelompokan sesuai dengan keseragaman dan relevansi. Kedua, menyangkut tingkat hubungan antara objek yang didasarkan pada kriteria tertentu.

\section{Langkah-Langkah Pengunaan AHP}

Menurut Pratiwi (2016:31) pada dasarnya prosedur atau langkah-langkah yang perlu diperhatikan dalam metode AHP, antara lain:

1. Mendefinisikan masalah dan menentukan solusi yang diinginkan.

2. Menentukan prioritas elemen

3. Membuat perbandingan berpasangan, yaitu membandingkan elemen secara berpasangan sesuai kriteria yang diberikan.

4. Matriks bilangan berpasangan diisi menggunakan bilangan untuk merepresentasikan kepentingan relatif dari suatu elemen terhadap elemen yang lainnya.

5. Sintesis

Pertimbangan -pertimbangan terhadap perbandingan berpasangan disintesis untuk memperoleh keseluruhan prioritas. Hal-hal yang dilakukan dalam langkah ini adalah :

a. Menjumlahkan nilai-nilai dari setiap kolom pada matriks.

b. Membagi setiap untuk memperoleh normalisasi matriks.

c. Menjumlahkan nilai-nilai dari setiap baris dan membaginya dengan jumlah elemen untuk mendapat nilai-rata-rata.

6. Mengukur Konsistensi
Dalam pembuatan keputusan , penting untuk mengetahui seberapa baik konsistensi yang ada karena kita tidak menginginkan keputusan berdasarkan pertimbangan dengan konsistensi yang rendah. Hal-hal yang dilakukan dalam langkah ini adalah:

a. Kalikan setiap nilai pada kolom pertama dengan prioritas relatif elemen pertama, nilai pada kolom kedua dengan prioritas relatif elemen kedua, dan seterusnya.

b. Jumlahkan setiap baris.

c. Hasil dari penjumlahan baris dibagi dengan elemen prioritas relatif yang bersangkutan.

d. Jumlahkan hasil bagi diatas dengan banyaknya elemen yang ada, hasil disebut $\lambda$ maks.

e. Hitung Consistency Index (CI) dengan rumus:

$\mathrm{CI}=(\lambda$ maks $-\mathrm{n}) / \mathrm{n}-1$

Dimana $n=$ banyaknya elemen berdasarkan sumber kriteria.Hitung rasio konsistensi/Consistency Index (CI) dengan rumus:

$$
\mathrm{CR}=\mathrm{CI} / \mathrm{IR}
$$

Dimana CR $=$ Consistency Ratio "hasil akhir dari perhitungan"

$\mathrm{CI}=$ Consistency Index "untuk mencari konsistensi index" $\mathrm{IR}=$ Index random consistency $\mathrm{CRH}=\mathrm{M} / \mathrm{M}^{\prime}$

f. Memeriksa konsistensi hirarki. Jika nilainya lebih dari $10 \%$, maka penilaian data judgement harus diperbaiki. Namun jika rasio konsistensi $(\mathrm{CI} / \mathrm{IR}) \leq 0.1$, maka hasil perhitungan bisa dinyatakan benar. Index random bisa dilihat pada tabel II.2.

Tabel II.2 Nilai Index Random

\begin{tabular}{|c|c|}
\hline Ukuran Matriks & Nilai IR \\
\hline 1,2 & 0,00 \\
\hline 3 & 0,58 \\
\hline 4 & 0,90 \\
\hline 5 & 1,12 \\
\hline 6 & 1,24 \\
\hline 7 & 1,32 \\
\hline
\end{tabular}




\begin{tabular}{|c|c|}
\hline 8 & 1,41 \\
\hline 9 & 1,45 \\
\hline 10 & 1,49 \\
\hline 11 & 1,51 \\
\hline 12 & 1,48 \\
\hline 13 & 1,56 \\
\hline 14 & 1,57 \\
\hline 15 & 1,59 \\
\hline
\end{tabular}

Sumber : (Pratiwi,2016)

\subsection{Expert Choice}

Menurut

(Warjiyono,2015)

mengemukakan bahwa "expert choice merupakan perangkat lunak yang digunakan untuk memecahkan masalah berdasarkan metode Analytical Hierarchy Process (AHP) yaitu membandingkan banyak alternatif kriteria-kriteria tertentu".

Menurut

(Warjiyono,2015) mengemukakan bahwa " expert choice menyediakan tools antara lain untuk analisa pengambilan keputusan, memberi keputusan yang lebih cepat serta keputusan akhir lebih baik serta dapat dibenarkan".

\section{METODE PENELITIAN}

Dalam melakukan suatu penyusuan skripsi ini, maka akan diperlukan beberapa langkah yang akan mencapai suatu tujuan penelitian itu sendiri.

\subsection{Tahapan Penelitian}

Adapun tahap-tahap pelaksanaan penelitian yang akan penulis lakukan sebagai berikut:

1. Identifikasi Masalah

2. Rumusan Masalah

3. Tujuan Masalah

4. Studi Pustaka Dan Studi Literatur

5. Pengumpulan Data

6. Pengolahan Data Metode AHP

7. Hasil Akhir \& Kesimpulan

\subsection{Instrumen Penelitian}

Dalam suatu proses penelitian, menurut Arikunto (2013:203) menyatakan bahwa"Instrumen penelitian adalah alat atau fasilitas yang digunakan oleh peneliti dalam mengumpulkan data agar pekerjaannya lebih mudah dan hasilnya lebih baik, dalam arti cermat, lengkap, dan sistematis sehingga lebih mudah dioalah.

Dalam penelitian ini instrumen penelitian yang digunakan adalah kuesioner yang berfungsi sebagai alat mengumpulkan datadata.

\subsection{Metode Pengumpulan Data, Populasi dan Sampel Penelitian}

\section{A. Teknik Pengumpulan Data}

Menurut Sugiyono (2016:224) Teknik pengumpulan data merupakan langkah yang paling strategis dalam penelitian, karena tujuan utama dari penelitian adalah mendapatkan data. Tanpa mengetahui teknik pengumpulan data, maka peneliti tidak akan mendapatkan data yang memenuhi standar data yang ditetapkan.

Dalam penelitian ini penulis menggunakan tiga metode dalam teknik pengumpulan datanya yaitu:

1. Observasi

Menurut Nasution dalam Sugiyono (2016:226) menyatakan bahwa" Observasi adalah dasar semua ilmu pengetahuan. Para ilmuwan hanya dapat bekerja berdasarkan data, yaitu fakta mengenai dunia kenyataan yang diperoleh melalui observasi”. Dalam penelitian ini peneliti melakukan observasi partisipatif secara lengkap, dimana dalam pengumpulan data peneliti sudah terlibat sepenuhnya terhadap apa yang dilakukan sumber data.

2. Wawancara

Menurut Esterberg dalam Sugiyono (2016:231) menyatakan bahwa" Wawancara adalah merupakan pertemuan dua orang untuk bertukar informasi dan ide melalui Tanya jawab, sehingga dapat dikonstruksikan makna dalam suatu topik tertentu". Wawancara dilakukan dengan Tanya jawab langsung 
antara penulis dengan narasumber mengenai tahapan yang dilakukan.

3. Kuesioner

Menurut Sugiyono (2016:142)

"Kuesioner merupakan teknik pengumpulan data yang dilakukan dengan cara memberi seperangkat pertanyaan atau pernyataan tertulis kepada responden untuk dijawabnya". Kuesioner dilakukan pada responden dimana akan menjadi data primer yang nantinya akan diolah.

\section{B. Populasi Penelitian}

Menurut Arikunto (2013:173) "Populasi adalah keseluruhan subjek penelitian. Apabila seseorang ingin meneliti semua elemen yang ada dalam wilayah penelitian, maka penelitiannya merupakan penelitian populasi". Populasi dalam penelitian ini adalah 10 masyarakat umum yang ada disekitar wilayah pada CV Darmin Motor Tangerang.

\section{Sampel Penelitian}

Menurut Sugiyono (2016:81) “ Sampel adalah bagian dari jumlah dan karakteristik yang dimiliki oleh populasi tersebut. Bila populasi besar dan peneliti tidak mungkin mempelajari semua yang ada pada populasi . misalnya karena keterbatasan dana,tenaga, dan waktu maka peneliti dapat menggunakan sampel yang diambil dari populasi itu". Pada penelitian ini jumlah populasi tidak diketahui sehingga sampel yang diambil adalah sebanyak 10 responden agar mewakili populasi secara keseluruhan.

\section{Teknik Pengambilan Sampel}

Menurut Sugiyono $(2016: 217)$ "Teknik
sampling adalah merupakan teknik
pengambilan sampel. Untuk menentukan
sampel yang akan digunakan dalam
penelitian, terdapat berbagai teknik sampling
yang digunakan".

\subsection{Metode Analisa Data}

Menurut Sugiyono (2016:7) Metode kuantitatif dinamakan metode tradisional, karena metode ini sudah cukup lama digunakan sehingga sudah mentradisi sebagai metode untuk penelitian. Metode ini disebut sebagai metode positivistic karena berlandasan pada filsafat positivism. Metode ini sebagai metode ilmiah/scientific karena telah memenuhi kaidah-kaidah ilmiah yaitu konkrit/empiris, obyektif, terukur, rasional, dan sistematis. Karena dengan metode ini dapat ditemukan dan dikembangkan berbagai iptek baru. Metode ini disebut metode kuantitatif karena ada penelitian berupa angka-angka dan analisis menggunakan statistik.

Menurut (Indarti \& Pribadi, 2017) Hasil dari data-data perbandingan berpasangan yang diambil dari kuesioner pada responden, kemudian dicari satu jawaban untuk matriks perbandingan dengan menggunakan perataan jawaban atau Geomatric Mean Theory. Untuk mendapatkan satu nilai tertentu dari semua nilai tersebut, masing-masing nilai harus dilakukan satu sama lain, kemudian hasil perkalian dipangkatkan dengan $1 / n$ dimana $\mathrm{n}$ adalah jumlah partisipan. Secara sistematis persamaan tersebut adalah sebagai berikut:

$$
a_{w}=\sqrt[n]{a_{2} x a_{2} x \ldots a_{n}}
$$

\section{ANALISA DAN PEMBAHASAN}

Metode yang akan digunakan dalam penelitian ini adalah Analytical Hierarchy Process (AHP) untuk menentukan suatu hasil penelitian dan pembahasan, dengan menggunakan prinsip dasar AHP yaitu : Decomposition, Comparative, Judgement, Synthesis of priority, Consistency.

\subsection{Penyusunan Hirarki}

Setelah suatu persoalan yang akan didefinisikan, maka akan dilakukan langkah selanjutnya yaitu memecahkan suatu persoalan yang utuh menjadi suatu unsur- 
unsurnya. Pemecahan persoalan tersebut akan digambarkan dalam suatu bentuk hirarki sebagai berikut.

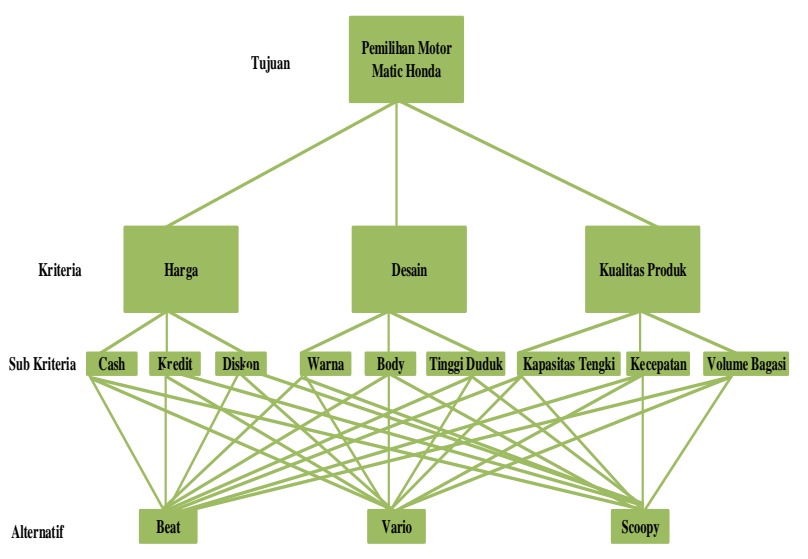

Tabel IV.9

Penjumlahan Nilai Kolom Kriteria Utama

\begin{tabular}{|c|c|c|c|}
\hline Kriteria & Harga & Desain & $\begin{array}{c}\text { Kualitas } \\
\text { Produk }\end{array}$ \\
\hline Harga & 1,000 & 3,272 & 1,380 \\
\hline Desain & 0,306 & 1,000 & 0,859 \\
\hline Kualitas Produk & 0,725 & 1,164 & 1,000 \\
\hline Total & 2,031 & 5,436 & 3,239 \\
\hline
\end{tabular}

Sumber : Penelitian 2018

Tahap kedua dari proses synthesis of priority adalah penjumlahan nilai kolom kriteria utama membuat normalisasi dari setiap kolom pada matrik perbandingan berpasangan dengan cara membagi nilai
Sumber: Penelitian 2018

\section{Gambar IV.1 Hirarki Pemilihan Sepeda Motor Matic Honda}

Hirarki diatas untuk menggambarkan suatu pemecahan masalah yang akan menjadi beberapa bagian, yaitu:
a. Level 0 Merupkan Tujuan
b. Level 1 Merupakan Kriteria Utama
c. Level 2 Merupakan Subkriteria dari setiap kriteria utama
d. Level 3 Merupakan suatu Alternatif, Merk Motor Matic Honda yang akan diipilih.

\subsection{Menentukan Prioritas (Synthesis of Priority)}

Proses yang akan dilakukan sesuai matriks perbandingan yang akan dibuat sebelumnya, proses synthesis of priority pada penelitian ini dapat dikerjakan sebanyak 13 kali, meliputi:

a. Level 1 Berdasarkan Kriteria Utama

Tahap pertama dari proses synthesis of priority adalah menjumlahkan nilai-nilai dari setiap sel pada setiap kolom.
Tabel IV.10

Normalisasi Kriteria Utama

\begin{tabular}{|c|l|c|c|}
\hline Kriteria & \multicolumn{1}{|c|}{ Harga } & Desain & $\begin{array}{c}\text { Kualitas } \\
\text { Produk }\end{array}$ \\
\hline Harga & $\begin{array}{l}1,000 / 2,03 \\
1=0,492\end{array}$ & $\begin{array}{l}3,272 / 5,4 \\
36=0,602\end{array}$ & $\begin{array}{c}1,380 / 3,2 \\
39=0,426\end{array}$ \\
\hline Desain & $0,306 / 2,03$ & $1,000 / 5,4$ & $0,859 / 3,2$ \\
& $1=0,151$ & $36=0,184$ & $39=0,265$ \\
\hline Kualitas & $0,725 / 2,03$ & $1,164 / 5,4$ & $1,000 / 3,2$ \\
Produk & $1=0,357$ & $36=0,214$ & $39=0,309$ \\
\hline
\end{tabular}

Sumber :Penelitian 2018

Tahap ketiga dari synthesis of priority adalah menghitung vektor eigen atau nilai rata-rata (local priority) dari masing-masing baris, dengan cara:

a. Menjumlahkan nilai-nilai sel dari setiap baris matrik.

b. Membagi masing-masing nilai dari operasi penjumlahan baris dengan skala yang merupakan total nilai sel.

Tabel IV.11

Vektor Eigen Kriteria Utama

\begin{tabular}{|c|c|c|c|c|}
\hline Kriteria & Harga & Desain & $\begin{array}{c}\text { Kualitas } \\
\text { Produk }\end{array}$ & $\begin{array}{c}\text { Rata- } \\
\text { rata }\end{array}$ \\
\hline Harga & 0,492 & 0,602 & 0,426 & 0,507 \\
\hline Desain & 0,151 & 0,184 & 0,265 & 0,200 \\
\hline $\begin{array}{c}\text { Kualitas } \\
\text { Produk }\end{array}$ & 0,357 & 0,214 & 0,309 & 0,293 \\
\hline Vektor & & & & 1,000 \\
\hline
\end{tabular}




\begin{tabular}{|c|l|l|l|l|}
\hline Eigen & & & & \\
\hline
\end{tabular}

Sumber : Penelitian 2018

Dari vektor eigen terlihat bahwa:

a. Kriteria Harga memiliki prioritas tertinggi dengan bobot 0,507

b. Kriteria Desain memiliki prioritas terendah dengan bobot 0,200

c. Kriteria Kualitas Produk memiliki prioritas kedua dengan bobot 0,293

Jadi urutan kriteria untuk pemilihan motor matic honda adalah:

1. Harga

2. Kualitas Produk

3. Desain

\subsection{Konsistensi Logis (Logical Consistency)}

Pada tahap ini akan menentukan keabsahan (ke-valid-an) vektor eigen yang diperoleh dari suatu proses synthesis of priority yang telah dibuat. Untuk penelitian ini proses Logical Consistency dikerjakan sebanyak empat kali, meliputi:

a. Level 1 berdasarkan kriteria utama.

1. Mengalikan matrik perbandingan berpasangan yang belum dinormalisir dengan vektor eigen.

$\left[\begin{array}{lll}1,000 & 3,272 & 1,380 \\ 0,306 & 1,000 & 0,859 \\ 0,725 & 1,164 & 1,000\end{array}\right] \times\left[\begin{array}{l}0,507 \\ 0,200 \\ 0,293\end{array}\right]=$

2. Hasil

$\left[\begin{array}{lll}0,507 & 0,654 & 0,404 \\ 0,155 & 0,200 & 0,252 \\ 0,368 & 0,233 & 0,293\end{array}\right]=\left[\begin{array}{l}1,566 \\ 0,607 \\ 0,893\end{array}\right]$

3. Perhitungan dengan vektor eigen.

$\left[\begin{array}{l}1,566 \\ 0,607 \\ 0,893\end{array}\right]:\left[\begin{array}{l}0,507 \\ 0,200 \\ 0,293\end{array}\right]=\left[\begin{array}{l}3,088 \\ 3,034 \\ 3,049\end{array}\right]$

4. Bagilah skala hasil operasi penjumlahan tersebut dengan banyaknya baris atau kolom dan hasil akhirnya akan menjadi nilai $\lambda$ maksimum.

$(3,088+3,034+3,049 / 3=3,057$

5. Menghitung index konsistensi (Consistency Index $=\mathrm{CI}$ ) dengan rumus :

$\mathrm{CI}=(\lambda$ maksimum $-\mathrm{n}) /(\mathrm{n}-1)$

$$
\left(\frac{3,057-3}{3-1}\right)=\left(\frac{0,057}{2}\right)=0,029
$$

Dimana $\mathrm{n}$ : banyaknya baris atau kolom matrik perbandingan berpasangan

6. Menghitung rasio konsistensi $($ Consistency Ratio $=\mathrm{CR})$ dengan rumus:

Dimana nilai RI: nilai nilai yang diacak yang diperoleh dari table Random Consistency Index pada $\mathrm{n}$ tertentu.

$$
\mathrm{CR}=\left(\frac{0,029}{0,58}\right)=0,049
$$

Dari perhitungan diatas diperoleh nilai CRH kurang dari 0,1 atau kurang dari 10\% maka hirarki keseluruhan bersifat konsisten, sehingga kesimpulan yang akan diperoleh dapat diterima, artinya keputusan yang telah ditetapkan dapat diandalkan.

\subsection{Hasil Penelitian Software Expert Choice 2000}

Setelah melakukan suatu perhitungan data secara manual dari hasil pengisian kuesioner, berikut ini adalah hasil input data dalam menggunakan software expert choice.

\section{Berdasarkan kriteria utama}

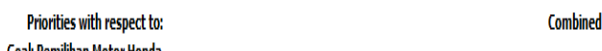

Goal: Pemilihan Motor Honda

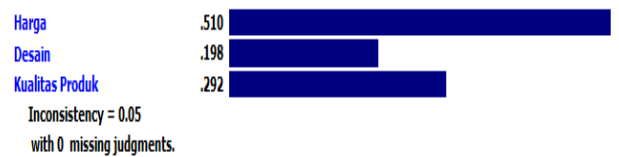

Gambar IV.3

Grafik hasil input data kriteria utama

Berdasarkan hasil pengolahan data diatas didapatkan bahwa hasil tertinggi yaitu kriteria harga dengan bobot nilai 0,510 atau 
$51,0 \%$. Kriteria ke dua adalah kualitas produk dengan bobot nilai 0,292 atau 29,2\%. Dan kriteria terakhir yaitu adalah desain dengan bobot nilai 0,198 atau $19,8 \%$.

\subsection{Hasil Akhir}

Setelah semua pembobotan alternatif dilakukan dengan semua kriteria, selajutnya akan melakukan perolehan hasil (sintesis) sekarang dapat dilakukan. Dibawah ini adalah grafik hasil perhitungan pada aplikasi expert choice.

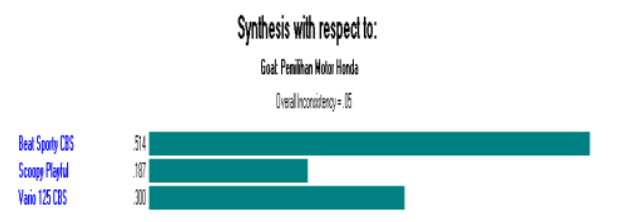

Gambar IV.10

Grafik Synthesize With Respect To Goal

\section{Dari perhitungan tersebut memperoleh hasil sebagai berikut:}

Tabel IV.61

Hasil Perhitungan Akhir dengan Expert Choice 2000

\begin{tabular}{|l|l|}
\hline Beat Sporty CBS & 0,514 \\
\hline Vario 125 CBS & 0,300 \\
\hline Scoopy Flayful & 0,187 \\
\hline Berdasarkan perhitungan akhir
\end{tabular}

tersebut pada aplikasi expert choice, maka merek motor matic honda Beat Sporty CBS mendapatkan perolehan nilai tertinggi dengan nilai 0,514 . Kemudian pilihan kedua Vario 125 CBS mendapatkan perolehan nilai 0,300. Dan diurutan ketiga Scoopy Flayful mendapatkan perolehan nilai 0,187 . Maka pada hasil ini menunjukan bahwa secara keseluruhan merek motor mactic honda dengan merek Beat Sporty CBS adalah yang paling banyak diminati oleh sebagian konsumen pada CV. Darmin Motor Tangerang karena memiliki perolehan nilai lebih tinggi dengan kriteria-kriteria lainnya, yaitu dengan nilai sebesar 0,514.

\section{KESIMPULAN}

Berdasarkan hasil penelitian yang dapat disimpulkan bahwa dari suatu kriteria-kriteria utama yang sudah ditentukan, terdapat suatu kriteria dengan prioritas tertinggi pada suatu pemilihan motor matic merek honda adalah pada kriteria harga dengan bobot nilai 0,507, selanjutnya prioritas kedua pada kriteria kualitas produk dengan bobot nilai 0,293 dan terakhir yang memiliki suatu prioritas terendah adalah kriteria desain dengan bobot nilai 0,200 .

Berdasarkan hasil perhitungan terakhir dengan menggunakan aplikasi expert choice, maka dalam penelitian ini penulis juga dapat menyimpulkan pada suatu pemilihan motor matic honda dengan merek Beat Sporty Cbs adalah merek yang paling banyak diminati oleh sebagian para konsumen karena memiliki perolehan nilai tertinggi dengan nilai 0,514 dibandingkan dengan suatu alternatif atau merek motor yang telah ditentukan pada proses penelitian pada CV. Darmin Motor Tangerang.

\section{REFERENSI}

[1] Arikunto, Suharsini. 2013. Prosedur Penelitian Suatu Pendekatan Peraktik. Jakarta: PT Rineka Cipta.

[2] Basuki, Ari dan Andharini Dwi Cahyani. 2016. Sistem Pendukung Keputusan. Yogyakarta: Deepublish.

[3] Indarti, dan Pribadi, D. 2017. Analytical Hierarchy Proses Sebagai Penunjang Sistem Pengambilan Keputusan Dalam Penilaian Pelayanan Pada TPU Wilayah Jakarta Utara. ISSN: 1978-1946. Jurnal Pilar Nusa Mandiri.Vol. 13, No. 2, September 2017: 187-192

http://ejournal.nusamandiri.ac.id/ejurnal/index.p hp/pilar/article/view/544

[4] Mongi, L., Mananeke, L., dan Repi, A. 2013. Kualitas Produk, Strategi Promosi Dan Harga Pengaruhnya Terhadap Keputusan Pembelian Kartu Simpati Telkomsel Di Kota Manado. ISSN: 2303-1174. Manado. Jurnal EMBA. Vol. 1, No. 4, Desember 2013: 2336-2346. https://ejournal.unsrat.ac.id/index.php/emba/artic le/view/3490/3019

[5] Oktafianto, Muhammad, M. 2016. Analisis Dan Perancangan Sistem Informasi. Yogyakarta: Andi Offset. 
[6] Pratiwi, Heny. 2016. Buku Ajar Sistem Pendukung Keputusan.Yogyakarta: Deepublish

[7] Putra, Dede W, T., dan Epriyano, M. 2017. Sistem Pendukung Keputusan Pemilihan Sepeda Motor Jenis Sport 150CC Berbasis Web Menggunakan Metode Analytical Hierarcy Process ( AHP ). ISSN: 2338-2724. Jurnal TEKNOIF. Vol. 5, No. 2, Oktober 2017:16-24. https://doi.org/10.21063/JTIF.2017.V5.2.16-24.

[8] Rianto, Bayu. 2017. Sistem Pengambilan Keputusan Pemilihan Sepeda Motor Menggunakan Metode Analytical Hierarchy Process (AHP) Studi Kasus: Sepeda Motor Sport Y amaha CB Rajawali Graha Motor. ISSN:2614-1299. Riau. Jurnal Teknik Industri UNISI. Vol. 1, No. 1, Desember 2017: 29-34. https://ejournal.unisi.ac.id/index.php/JUTI/articl e/view/47/47

[9] Rianto, Bayu dan Halen, Rico V. 2016. Penerapan Metode AHP Untuk Pemilihan Kendaraan Sepeda Motor Matic Studi Kasus Dialer Honda Peranap. ISSN: 2460-0679. Riau. Riau Journal Of Computer Science.Vol. 2, No. 1, 2016: 1322.

http://e-

journal.upp.ac.id/index.php/RJOCS/article/view/ $778 / 607$

[10] Rizaldi. 2017. Penentuan Operator Kartu Seluler Terbaik Menggunakan Metode AHP (Analitycal Hierarchy Process). ISSN: 2580-7927. Jurnal Teknologi Informasi. Vol. 1, No. 1, Juli 2017: 67-73.

http://jurnal.una.ac.id/index.php/jurti/article/vie w/44/41

[11] Rizky, Fakhru M dan Hanifa Yasin. 2014. Pengaruh Promosi Dan Harga Terhadap Minat Beli Perumahan Obama PT. Nailah Adi Kurnia Sei Mencrim Medan. ISSN: 1693-7619. Medan. Jurnal Manajemen \& Bisnis. Vol. 14, No. 02, 2014: 135-143.

[12] Saefudin, dan Sri Wahyuningsih. 2014. Sistem Pendukung Keputusan untuk Penilaian Kinerja Dosen Meggunakan Metode Analytical Hierarchy Process (AHP) Pada RSUD Serang. ISSN: 2406-7768. Jurnal Sistem Informasi. Vol. 1, No. 1, 2014: 33-37. http://digilib.uin-suka.ac.id/7334/2

[13] Sasongko, Aji, Fitri Astuti, I., Dan Maharani, S. 2017. Pemilihan Karyawan Baru Dengan Metode AHP Anallic Hierarchy Process. Samarinda. ISSN: 1858-4853. Jurnal Informatika Mulawarman. Vol. 12, No. 2 September 2017: 88-93.

[14] Sugiyono. 2016. Metode Penelitian Kuantitatif, Kualitatif, Dan R \& D. Bandung: Alfabeta Cv.

[15] Warjiyono. 2015. Analisis Faktor Pemilihan Perguruan Tinggi Di Tegal Berdasarkan Jenjang Pendidikan Menggunakan Metode Analytical Hierarchy Process (AHP). Tegal. ISSN: 23388161. Jurnal Evolusi. Vol. 3, No. 2 2015:33-38. 